\title{
Factors Influencing Weight Loss Attempts and Long Term Weight Loss Maintenance
}

\author{
Souad El-mani ${ }^{1}$, Ali Ateia Elmabsout ${ }^{1}$, Abdullah Sheikhi ${ }^{2}$, Reima Mansour ${ }^{3}$, \\ Fawzia M Salem Bozaid ${ }^{1}$, Hind Alkadiky ${ }^{1}$, Hajer Albarghati ${ }^{1}$, Sara Benghazy ${ }^{1}$, \\ Nada Jamal ${ }^{1}$
}

\author{
${ }^{1}$ Department of Nutrition, Faculty of Public Health, University of Benghazi, Libya \\ ${ }^{2}$ Curtin University, Perth, Western Australia \\ ${ }^{3}$ School of Science and Health, Western Sydney University, Australia
}

Corresponding Author: Souad El-mani

\begin{abstract}
Background: A cross-sectional study aimed to determine the factors association with repeated weight loss attempts, and weight loss maintenance.

Methods: The study was conducted in the main public hospitals in Benghazi, Libya. A total sample of 300 participants who suffered from weight gain or/ obesity and had a history of trying of weight loss. The data were collected by using a questionnaire that include all the factors that may affect the weight loss process such as social, psychological, health, factors related to diet, and daily behavior factors.

Results: The majority of participants $78 \%$ were found at age group between $15-35$ years, $81.7 \%$ of them were female and $18.3 \%$ were male. More than half of participants $56 \%$ had less than four times of weight loss attempts, while $43.6 \%$ of them had more than four attempts. The repetition of weight loss attempts was associated with genetic, binge eating, tension, anxiety, negative body image, duration of weight loss maintenance, watching TV or online hours, and eating rate. Around half of participant $55.6 \%$ had less than one of successful attempts, while $44.3 \%$ had more than one attempts. The factors associated with the successful attempt of weight loss were using weight loss medications, the rate of weight loss, aware food serving, eating breakfast, and exercise. The higher number of attempts of weight lose was associated with higher successful attempt (more than one attempt) $\mathrm{P}=(0.031)$.

Conclusions: Psychological factors were the most factors affected on repeating weight loss attempts followed by behavior related factors. Practices related to self-control, mental control, stress reduction, and behavior modification should be considered at any weight loss management program. Body weight loss programs need strike follow up by dietician in order to avoid the fluctuations in body weight.
\end{abstract}

Keywords: The factors weight loss, weight loss attempts, successful weight loss attempts, weight loss maintenance.

\section{INTRODUCTION}

In the recent years, obesity is considered as a chronic disease being also as a severe individual health condition and an important public health issue. Obesity results from accumulation of body fat which leads to severe complications and a significant increase of mortality rate. ${ }^{1}$ In 2017-2018 the prevalence of obesity in
United States was increased among all the age group of adult people that include , adults aged 20-39, adults aged 40-59, and adults aged 60 and over, about $40 \%$ $44.8 \%, 42.8 \%$, respectively. The prevalence of obesity was also high among the childhood period, in 2009 about 38 million of children under the age of 5years in the United States were overweight or obese. ${ }^{2}$ 
Globally, The prevalence of overweight and obesity as a public health concern is well established and reflects the overall lack of success in the ability to achieve and maintain a healthy body weight. There are many factors affect the ability of obese patients to lose weight and maintain a healthy body weight. ${ }^{2}$

First of all social factors, Most of the previous studies that focused on weight loss indicated that there are variation between weight loss and body composition, age, occupation, and socioeconomic status of patients. American studies showed that there was significant difference between age group and the percentage of excess BMI loss, the better results of weight loss and reducing of complications were observed among younger patients ${ }^{3,4}$ A number of characteristics of men and women that also contribute to the difference in weight loss success. According to the National Health and nutrition Examination survey III (NHANES III) showed that female aged between 12to 80 years had higher percentage of Fat Mass (FM) than male , the estimated of total body weight and Free Fat Mass increased in all racial_ ethnic groups and in all age group of female. ${ }^{5} \mathrm{~A}$ cohort study found that there was effect of exercise on the body weight and body composition of both male and female, the men who did the exercises lost $5.2 \mathrm{~kg}$ of weight, equivalent to $6 \%$ of the basic weight. As for the women, the exercises did not lead to weight loss but prevented an increase weight about $3 \mathrm{~kg}$ for the control group. ${ }^{6}$ Another American study was conducted to assess the relationship between dieting and weight change and race /ethnicity adolescence and young adulthood reported that dieting to lose weight was ineffective, and it is actually associated with greater weight gain, particularly among female adolescent. There was variation also among participants in the number of attempts times of weight lose, Hispanics (58.0\%) were more likely than whites (55.2\%) to be trying to lose weight. ${ }^{7}$
The second factors that affect weight loss are heath factors, the obese people with other diseases such as diabetes mallets, cancers or breast cancer, and ovarian cysts thyroid diseases are needed to weight loss to improve clinical results, reduce complications, and accelerate treatment effect. $^{8}$ American study indicated that increased BMI $>40 \mathrm{~kg} / \mathrm{m} 2$ was associated with increased death rates for all cancer types. ${ }^{9}$ Spanish study also found that the weight of hypothyroid patients decreased from $70.93 \pm 10.06 \mathrm{~kg}$ to $68.68 \pm 10.14$ $(p=0.000)$, while the weight of hyperthyroid patients increased from $65.45 \pm 11.64 \mathrm{~kg}$ to $68.37 \pm 12.80(\mathrm{p}=0.000) .{ }^{10}$ The results of this study showed that there was an association between obesity and BMI $\left(>30 \mathrm{~kg} / \mathrm{m}^{2}\right)$ and slightly elevated serum TSH levels ( $p$ 0.001). ${ }^{10}$ Another previous study suggest that use of pharmacological treatment could be benefit to loss of body weight. American studies describe use of pharmacotherapy like (Fluoxetine, orlistat, and sibutramine) in weight loss for diabetic patients and use orlistat for ovarian cysts patients. These drugs achieved statistically significant weight loss for 26 to 52 weeks, Fluoxetine (5.8 kg at 52 weeks), orlistat (2.6 kg at 52 weeks). ${ }^{11.12}$

Psychological factors are considered as important effective factors on weight lose and maintenance. A previous study was conducted in United States indicated that weight gain was associated with increasing levels of psychosocial stress related to jobrelated demands $(\mathrm{P}<0.001)$, that include lack of skill discretion, lack of decision authority and difficulty paying bills among male while Among women were strain in relations with family. ${ }^{13}$ Furthermore, Tunisian study was conducted to determine the satisfaction rate of female on their body shape, this study found that almost twothirds of all women were dissatisfied with their current body size. A normal body size (BMI 20-24 kg/m) was seen in the most positive light by Tunisian women. ${ }^{14}$ The other psychological factors is increases the desire to eat, especially among those follow 
restricted diet compared with non-dieters.. ${ }^{15}$ According to experiment study found that (71\%) of participants are restrained eaters (i.e., dieters) report increasing food consumption when stressed than are people who under eat or who do not change the amount they eat when stressed (35\%). ${ }^{16}$

The last factors are dietary and behavioral factors, there are a large number of dietary programs that are available in different websites. Many of these dietary programs are based on scientific evidence of weight loss. However, qualitative research suggests that successful dieters depend on their understandings about dietary intake (quality and quantity), emotional challenges, and surrounding environment. ${ }^{17}$ A previous study found that long-term diet attempts were not functional in the general population, as BMI and WC showed an increase in dieters than non-dieters. 18 Another study was conducted in America that showed that only $31 \%$ of the people reported successful weight loss attempts, and this study recommended that selfmonitoring strategies such as weighing oneself, choosing an appropriate meals, exercising 30 or more minutes daily, may be important in successful weight loss maintenance. ${ }^{19}$ European study showed that increase of protein content in diet and deceasing high glycemic index led to an improvement in maintenance of weight loss. The weight regain was $0.93 \mathrm{~kg}$ less in the groups followed a high-protein diet than in those followed a low-protein diet $(\mathrm{P}=0.003){ }^{20}$

Life style behavior such as watching TV contributes to affecting on weight loss or maintaining weight loss. Raynor and et.al found that that the number of hours of sitting on TV associated with weight loss, increases in TV watching hours were significant predictors for regain weight of one year. ${ }^{21}$ furthermore, skipping breakfast led to increase prevalence of obesity. According to previous study found that around half of participants who are breakfast skipper suffered from obesity. ${ }^{22}$ Clinical studies confirmed that regular consumption of meals reduced the risk of obesity and chronic diseases. ${ }^{23}$ In addition, number of previous studies concluded that obesity is associated with a self-reported short sleep duration and sleep disturbances. The short sleep duration is caused by emotional stress as reported by obese people. ${ }^{24,25}$

Because obesity is a chronic disease, maintenance of weight loss is included as a standard of success, and the response to obesity treatment varies according to different factors. There are few studies targeting the factors that defined weight loss successful, therefore, this study aimed to determine factors influencing weight loss success and long term weight loss maintenance, and to

1. study the personal and social aspect and its effect on the number of weight loss attempt.

2. know the effect of health conditions and diseases (chronic diseases) on the number of weight loss attempt.

3. study of the psychological factors and its effect on the weight loss attempt.

\section{METHOD AND MATERIAL}

Study Population: A cross-sectional study was conducted in Benghazi, Libya in 2020 to determine the factors affecting weight loss process for a specific age group from 15 to 65years. The total numbers of participants were 300 participants, including 51 men and 249 women.

Data collection methods: questionnaire that was prepared and distributed to the participants in some public hospitals as well as over the Internet. This questionnaire contains 34 questions covering all aspects related to the process of weight loss, 4 elements were about personal information such as (age, gender, educational level, profession, working hours). In addition, other questions asked about the health condition that include presence of diseases, type of medication, and duration of intake. Other questions asked about aspects related to the situation (social, psychological, genetic) and its impact on repeated weight 
loss attempts and the number of successful weight loss attempts. The next questions asked about dietary history that include: (source of diet, duration of follow-up, diet sources, weight loss per week, duration of maintains weight loss). The questionnaire also contains information about the daily behaviors such as hours on TV or online, water consumption, regularity in breakfast, exercise, place of eating, sharing eating, eating duration, and hours of sleep.

\section{Measurement:}

Weight and height were measured by the researchers after completion of the questionnaires. Height was measured to the nearest $0.1 \mathrm{~cm}$ using standard calibrated scale attached to the balance against wall. Weight was measured to the nearest $0.2 \mathrm{~kg}$ using weighting machine. During measuring body weight, participants were wearing light clothes and thin socks or bare feet, BMI was computed as body weight in (Kg) divided by body height in (m) squared and the body mass index was calculated and classified according to WHO classification.

\section{Statistical analysis:}

The Statistical Package for the Social Sciences (SPSS) version 21.0 was used to analyze the data. Descriptive statistical tests were conducted to make comparison including frequencies and Chi square test with (95\%) confidence intervals. Chi-squared analysis was used to compare different factors with number of weight loss attempt and number of successful weight loss attempt. All p values $<0.05$ were considered statistically significant.

\section{Ethical statement:}

This study was approved by university of Benghazi and all questionnaires were anonymous and unidentified to ensure the confidentiality of collected information.

\section{RESULT}

\section{Demographical characteristics of participants:}

Total participants in this study were $\mathrm{N}=300$ persons, $81.7 \%$ of them were females and $18.3 \%$ were males with ages range from 15 to 55 years. The majority of participants $78 \%$ were with age $15-35$ year while only $2 \%$ of them were with an age group more than 55 years. The most of participants $87 \%$ were with high educated level (university degree), while $1 \%$ of them were uneducated. less than half of participants $47 \%$ were officers, and $51 \%$ of them worked for period range from 46hours. More than half of participants 57\% were with income 500-1000, and more than half of them also $56.3 \%$ were unmarried. See table 1

\begin{tabular}{|c|c|c|}
\hline Characteristics & Frequency & Percent \\
\hline \multicolumn{3}{|l|}{ Age } \\
\hline $15-35$ & 243 & $78 \%$ \\
\hline $35-55$ & 60 & $20 \%$ \\
\hline$>55$ & 6 & $2 \%$ \\
\hline \multicolumn{3}{|l|}{ Sex } \\
\hline Female & 245 & $81.70 \%$ \\
\hline Male & 55 & $18.30 \%$ \\
\hline \multicolumn{3}{|l|}{ Education level } \\
\hline Uneducated & 4 & $1.3 \%$ \\
\hline primary & 2 & $7 \%$ \\
\hline Secondary & 33 & $11 \%$ \\
\hline University & 261 & $87 \%$ \\
\hline \multicolumn{3}{|l|}{ Occupation } \\
\hline Unemployed & 4 & $1.3 \%$ \\
\hline Student & 58 & $19.3 \%$ \\
\hline Officer & 141 & $47 \%$ \\
\hline house wife & 78 & $26 \%$ \\
\hline free business & 19 & $6.3 \%$ \\
\hline \multicolumn{3}{|l|}{ Work hours } \\
\hline $1-3$ & 85 & $28.3 \%$ \\
\hline $4-6$ & 154 & $51.3 \%$ \\
\hline $7-9$ & 50 & $16.7 \%$ \\
\hline $10-12$ & 11 & $3.7 \%$ \\
\hline \multicolumn{3}{|l|}{ Income level } \\
\hline 500 & 57 & $19 \%$ \\
\hline $500-1000$ & 171 & $57 \%$ \\
\hline$>1000$ & 72 & $24 \%$ \\
\hline \multicolumn{3}{|l|}{ Social status } \\
\hline Single & 169 & $56.3 \%$ \\
\hline Married & 131 & $43.7 \%$ \\
\hline Total & 300 & $100 \%$ \\
\hline
\end{tabular}

In regarding to BMI, female presented the highest numbers of over weight than male $26.90 \%$ vs. $5.90 \%$ respectively. Obese grade I was higher than other grads among female participants and also female still shown highest percentages $24.90 \%$ vs. $5.60 \%$, $11.90 \%$ vs. $3 \%$ and $3.50 \%$ vs. $1.40 \%$ for obese I , grade II and grade III respectively. There was clear relation between working hours, marital status, and number of children, $\mathrm{p}$. value $=0.000,0.008$, and 0.017 respectively. There was also relationship 
between BMI level with weight loss attempts $\mathrm{p}=(0.003)$.

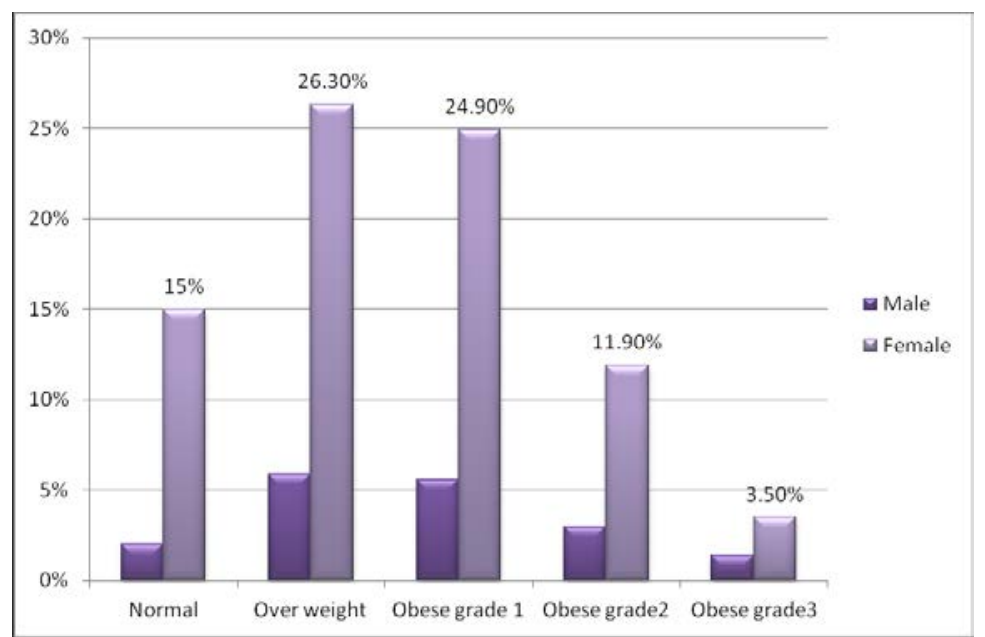

Figure 2: Distribution of BMI level among participants

Medical history of participants: -

In regarding to medical history of participants, table 2 showed that more than half of participants $68.6 \%$ did not have any health problems, and $31 \%$ of them had some health problems that include (30.8\% ovarian polycystic, $12.7 \%$ thyroid disease, and $7 \%$ diabetes). Half of the participants 50\% were taking treatment that include (25\% weight loss drugs, $9.7 \%$ contraindications drugs, and $47.2 \%$ other drugs). Also more than half of participants $67.6 \%$ had obesity in their family history.

\begin{tabular}{|c|c|c|c|c|}
\hline Health factors & weight loss attempts $<4$ & weight loss attempts $>4$ & Total & P value \\
\hline \multicolumn{5}{|l|}{ Health problems } \\
\hline Yes & $46(27.2 \%)$ & $48(36.6 \%)$ & $94(31.3 \%)$ & \multirow{2}{*}{0.053} \\
\hline No & $123(72.7 \%)$ & $83(63 \%)$ & $206(68.6 \%)$ & \\
\hline \multicolumn{5}{|l|}{ Diseases } \\
\hline Diabetes mellitus & $3(6.5 \%)$ & $4(8.3 \%)$ & $7(7.4 \%)$ & \multirow[t]{4}{*}{0.299} \\
\hline Thyroid diseases & $8(17.3 \%)$ & $4(8.3 \%)$ & $12(12.7 \%)$ & \\
\hline ovarian polycystic & $14(30.4 \%)$ & $15(31.2 \%)$ & $29(30.8 \%)$ & \\
\hline other diseases & $21(45.6 \%)$ & $25(52.0 \%)$ & $46(48.9 \%)$ & \\
\hline \multicolumn{5}{|l|}{ Treatment } \\
\hline Yes & $78(46.1 \%)$ & $72(54.9 \%)$ & $150(50 \%)$ & \multirow[t]{2}{*}{0.081} \\
\hline No & $91(53.8 \%)$ & $59(45.0 \%)$ & $150(50 \%)$ & \\
\hline \multicolumn{5}{|l|}{ Type of treatments } \\
\hline Contraindications & $16(20.5 \%)$ & $7(9.7 \%)$ & $23(15.3 \%)$ & \multirow[t]{6}{*}{0.309} \\
\hline Diabetes drugs & $4(5.1 \%)$ & $5(6.94 \%)$ & $9(6 \%)$ & \\
\hline Cortisol & $3(3.8 \%)$ & $4(5.5 \%)$ & $7(4.6 \%)$ & \\
\hline Thyroid drugs & $7(8.9 \%)$ & $4(5.5 \%)$ & $11(7.3 \%)$ & \\
\hline weight loss drugs & $12(15.3 \%)$ & $18(25 \%)$ & $30(20 \%)$ & \\
\hline other drugs & $36(46.1 \%)$ & $34(47.2 \%)$ & $70(46.6 \%)$ & \\
\hline \multicolumn{5}{|l|}{ Heredity* } \\
\hline Yes & $104(61.5 \%)$ & $99(98.5 \%)$ & $203(67.6 \%)$ & \multirow[t]{2}{*}{0.007} \\
\hline No & $65(38.4 \%)$ & $32(18.9 \%)$ & $97(32.3 \%)$ & \\
\hline Total & 169 & 131 & 300 & \\
\hline
\end{tabular}

This study was based on studying some factors that include medical history to determine the extent of their influence on the frequency of weight loss attempts. From the total of participants $n=300$ who had repeated experiences of weight loss, 56.3\% of them had less than 4 times of weight loss attempts , and $43.6 \%$ of them had more than
4 times of weight loss attempts. Table 2 indicted that there was no significant relationship between weight loss attempts times and medical history that include health problems, taking medicine and types of treatment with exception with hereditary factors. There was a significant relationship between weight loss attempts and hereditary 
factor p.value $<0.05$. The number of weight loss attempts 'times were more among participants who had obesity in their family history than who did not have hereditary obesity, (67.6\% vs. $32.3 \%$, p.value=0.007). See table

Table 3: The relation between psychological factors and number of attempts to weight loss among participants.

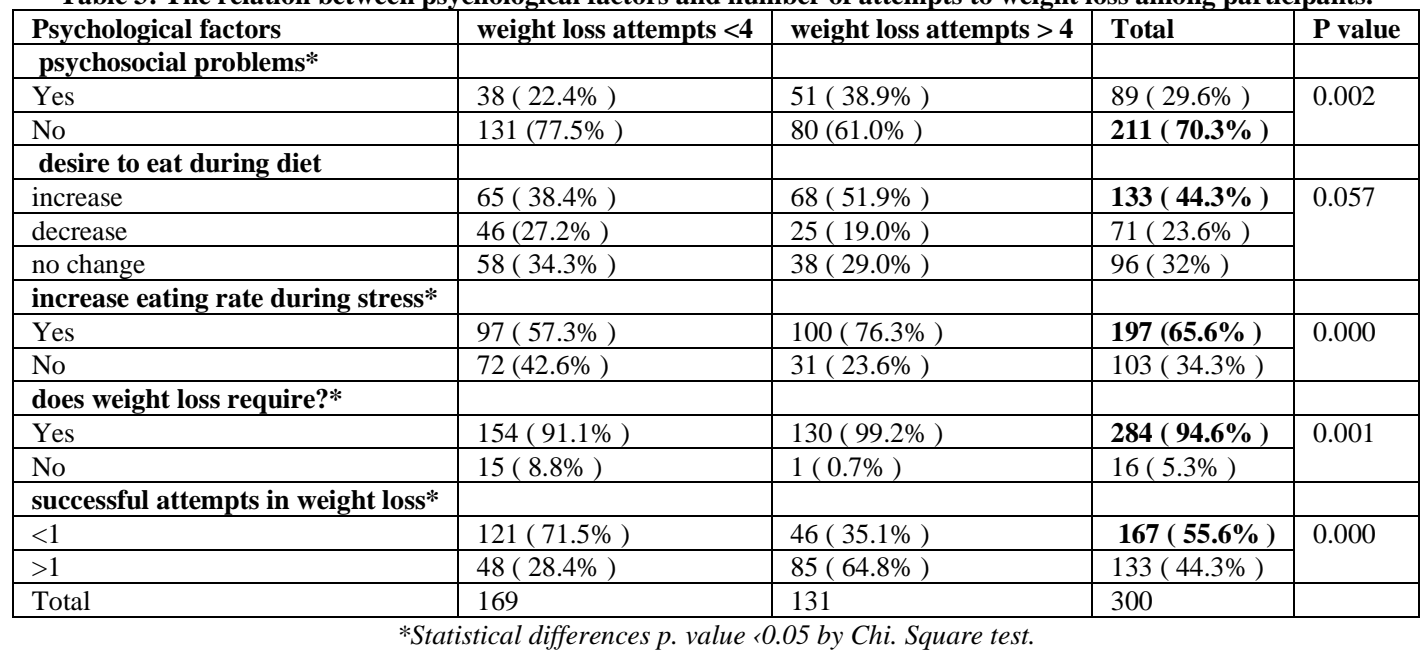

As shown in Table (3), there was significant relation between psychological factors and number of weight loss attempts. First of all, there was a relationship between the number of trying to lose weight and psychological problems, $(22.4 \%$ of participants had fewer than 4 attempts of weight lose vs.38.9\% had more than 4 attempts of weight loss, $\mathrm{P}=0.002$. Approximately half of participant $44.3 \%$ had increase desire to eat during following specific diet, $51.9 \%$ of them had more than 4 attempts of weight loss, while $38.4 \%$ of them had less than 4 attempts of weight loss. Additionally, more than half of participants $65.6 \%$ were eating more during stress. There was a significant correlation between participants' psychological status and number of attempts to weight loss, $76.3 \%$ of participants had more than 4 attempt and $57.3 \%$ of them had less than 4 attempts $\mathrm{P}=(0.000)$. More fore, the majority of participants $94.6 \%$ believed that weight loss is needed, there was a relationship between their need to lose weight and attempts to lose weight. Participants who believed weight loss is required had more attempts ( $>4$ times) of weight loss than those did not believe that, (99.2\% vs. $0.7 \%, \mathrm{P}=0.001)$. There was also association between successful weight loss and number of attempts of weight loss, more than half of participants $64.8 \%$ who had increase number of successful weight loss had more number of weight loss attempts than who had less number of successful weight loss $(64.8 \%$ vs. $35.1 \%, p=0.000)$. See Table 3

\section{Dietary pattern and behavior of participants:-}

In regarding to dietary factors, the minority of participants $7 \%$ were followed diet that is described by nutritionists and $18 \%$ of them by their self, while the majority of participants $75 \%$ were followed described diet by both nutritionist and by theirself. The majority of participants $82 \%$ also had diet from different sources of foods (an integrated diet), $83.4 \%$ of them had less than 4 attempts, and $80.1 \%$ had more than 4 attempts. Less than half of participants 39\% followed a diet for less than a year, and $48.6 \%$ of them lose weight from $0.5-1 \mathrm{~kg}$ in a week. There was significant association between number of attempts weight loss and weight loss maintenance. Most of participants $50.8 \%$ who have weight loss maintained for less than one years had increase number of weight loss attempts (more than 4 times) than those maintained 
their weight loss more than one years. (50.8\% vs. $24.3 \%$, $\mathrm{p}=0.002)$.See Table 4

\begin{tabular}{|c|c|c|c|c|}
\hline Dietary factors & weight loss attempts $<4$ & weight loss attempts $>4$ & Total & P value \\
\hline \multicolumn{5}{|l|}{ Source of diet } \\
\hline dietitian & $10(5.9 \%)$ & $11(8.39 \%)$ & $21(7 \%)$ & \multirow[t]{3}{*}{0.218} \\
\hline yourself & $37(21.8 \%)$ & $19(14.5 \%)$ & $56(18.6 \%)$ & \\
\hline both & $122(72.1 \%)$ & $101(77.0 \%)$ & $223(74.3 \%)$ & \\
\hline \multicolumn{5}{|l|}{ Diet sources } \\
\hline protein & $14(8.28 \%)$ & $9(6.8 \%)$ & $23(7.6 \%)$ & \multirow[t]{4}{*}{0.586} \\
\hline fat & $3(1.7 \%)$ & $3(2.29 \%)$ & $6(2 \%)$ & \\
\hline protein and $\mathrm{CHO}$ & $11(6.5 \%)$ & $14(10.6 \%)$ & $25(8.3 \%)$ & \\
\hline integrated diet & $141(83.4 \%)$ & $105(80.1 \%)$ & 246 ( 82\% ) & \\
\hline \multicolumn{5}{|l|}{ follow up diet } \\
\hline less than a month & $27(15.9 \%)$ & $26(19.8 \%)$ & $53(17.6 \%)$ & \multirow[t]{5}{*}{0.168} \\
\hline a month & $42(24.8 \%)$ & $36(27.4 \%)$ & $78(26 \%)$ & \\
\hline less than one year & $70(41.4 \%)$ & $47(35.8 \%)$ & $117(39 \%)$ & \\
\hline year & $19(11.2 \%)$ & $7(5.3 \%)$ & $26(8.6 \%)$ & \\
\hline more than one year & $11(6.5 \%)$ & $15(11.4 \%)$ & $26(8.6 \%)$ & \\
\hline \multicolumn{5}{|l|}{ weight loss per week } \\
\hline $0.5-1 \mathrm{~kg}$ & $85(50.2 \%)$ & $61(46.5 \%)$ & $146(48.6 \%)$ & \multirow[t]{3}{*}{0.421} \\
\hline $2-4 \mathrm{~kg}$ & $66(39.0 \%)$ & $60(45.8 \%)$ & $126(42 \%)$ & \\
\hline$>4 \mathrm{~kg}$ & $18(10.6 \%)$ & $10(7.6 \%)$ & $28(9.3 \%)$ & \\
\hline \multicolumn{5}{|c|}{ Maintenance weight loss* } \\
\hline less than one year & $86(50.8 \%)$ & $91(69.4 \%)$ & 177 (59\%) & \multirow[t]{3}{*}{0.002} \\
\hline one year & $30(17.7 \%)$ & $20(15.2 \%)$ & $50(16.6 \%)$ & \\
\hline more than one year & $53(31.3 \%)$ & $20(15.2 \%)$ & $73(24.3 \%)$ & \\
\hline Total & 169 & 131 & 300 & \\
\hline
\end{tabular}

Table 5 focuses on behavioral factors, showed that there is association between participants' behavior and the number of weight loss attempts. The participants who were watching TV for long period of time had more number of weight loss' attempts than those watching TV for 12 hrs $(43.5 \%$ vs. 21.3\%, p.value $=0.01)$. Approximately, half of participants $50.6 \%$ were eating food on the ground compared to those eating food in a chair, and more than half of participants $56.3 \%$ were sharing food with their family. Additionally, the majority of participants $74 \%$ were drinking enough water, and more than half of participants $62 \%$ were eating Breakfast regularly. The most of participants $62.3 \%$ were practicing sports, and $41.3 \%$ of people slept less than 8 hours. There was no relation between eating pattern, sleeping hours, and exercise with number of weight loss attempts. On other hand, there was a clear relationship between weight loss attempts and duration of eating, $\mathrm{P}=(0.023)$.

Table 5 Description the relation between participants' behavior and weight loss attempts .

\begin{tabular}{|c|c|c|c|c|}
\hline Behavior factors & weight loss attempts $<4$ & weight loss attempts $>4$ & Total & P value \\
\hline \multicolumn{5}{|l|}{ hours on TV or internet* } \\
\hline $1-2$ hours & $53(31.3 \%)$ & $28(21.3 \%)$ & $81(27 \%)$ & \multirow[t]{3}{*}{0.01} \\
\hline $2-5$ hours & $70(41.4 \%)$ & $46(35.1 \%)$ & $116(38.6 \%)$ & \\
\hline more than 5 & $46(27.2 \%)$ & $57(43.5 \%)$ & $103(78.6 \%)$ & \\
\hline \multicolumn{5}{|l|}{ Water Consumption } \\
\hline Yes & $127(75.1 \%)$ & $95(72.5 \%)$ & $222(74 \%)$ & \multirow[t]{2}{*}{0.35} \\
\hline No & $42(24.8 \%)$ & $36(27.4 \%)$ & $78(26 \%)$ & \\
\hline \multicolumn{5}{|l|}{ Breakfast } \\
\hline Yes & $103(60.9 \%)$ & $83(63.3 \%)$ & $186(62 \%)$ & \multirow[t]{2}{*}{0.38} \\
\hline No & $66(39.0 \%)$ & $48(36.6 \%)$ & $144(38 \%)$ & \\
\hline \multicolumn{5}{|l|}{ Exercise } \\
\hline Yes & $100(59.17 \%)$ & $87(66.4 \%)$ & $187(62.3 \%)$ & \multirow[t]{2}{*}{0.122} \\
\hline No & $69(40.8 \%)$ & $44(33.5 \%)$ & $113(37.6 \%)$ & \\
\hline \multicolumn{5}{|l|}{ place of eating } \\
\hline Chair & $82(48.5 \%)$ & $66(50.3 \%)$ & $148(49.3 \%)$ & \multirow[t]{2}{*}{0.419} \\
\hline Ground & $87(51.4 \%)$ & $65(49.6 \%)$ & $152(50.6 \%)$ & \\
\hline \multicolumn{5}{|l|}{ Sharing eating } \\
\hline Family & $101(59.7 \%)$ & $68(51.9 \%)$ & $169(56.3 \%)$ & \multirow[t]{2}{*}{0.107} \\
\hline Alone & $68(40.3 \%)$ & $63(48.0 \%)$ & $131(43.6 \%)$ & \\
\hline \multicolumn{5}{|l|}{ Eating duration* } \\
\hline $10 \mathrm{~min}$ & $68(40.2 \%)$ & $69(52.6 \%)$ & $137(45.6 \%)$ & 0.023 \\
\hline
\end{tabular}




\begin{tabular}{|c|c|c|c|c|}
\hline $15 \mathrm{~min}$ & $72(42.6 \%)$ & $36(27.4 \%)$ & $108(36 \%)$ & \\
\hline $20 \mathrm{~min}$ & $20(11.8 \%)$ & $13(9.9 \%)$ & $33(11 \%)$ & \\
\hline More & $9(5.3 \%)$ & $13(9.9 \%)$ & $22(7.3 \%)$ & \\
\hline Hours of sleep & & & & \\
\hline less than 8 hours & $68(40.2 \%)$ & $56(42.7 \%)$ & $124(41.3 \%)$ & \multirow[t]{3}{*}{0.54} \\
\hline 8 hours & $59(34.9 \%)$ & $38(29.0 \%)$ & $97(32.3 \%)$ & \\
\hline more than 8 hours & $42(24.8 \%)$ & $37(28.2 \%)$ & $79(26.3 \%)$ & \\
\hline Total & 169 & 131 & 300 & \\
\hline
\end{tabular}

\section{Relation between successful weight loss and other factors:}

Table 6 : Relationship between the study factors with successful weight loss attempts.

\begin{tabular}{|c|c|c|c|c|}
\hline Variables & successful attempts $<1$ & successful attempts $>1$ & Total & P value \\
\hline \multicolumn{5}{|l|}{ Type of drug* } \\
\hline Contraindications & $19(23.4 \%)$ & $4(5.7 \%)$ & $23(15.3 \%)$ & \multirow[t]{6}{*}{0.030} \\
\hline Diabetes drugs & $7(8.6 \%)$ & $4(5.7 \%)$ & $11(7.3 \%)$ & \\
\hline Cortisol & $2(2.4 \%)$ & $3(4.3 \%)$ & $5(3.3 \%)$ & \\
\hline Thyroid drugs & $4(4.9 \%)$ & $7(10.1 \%)$ & $11(7.3 \%)$ & \\
\hline weight loss drugs & $12(14.8 \%)$ & $18(26.0 \%)$ & $30(20 \%)$ & \\
\hline other drugs & $37(45.6 \%)$ & $33(47.8 \%)$ & $70(46.6 \%)$ & \\
\hline \multicolumn{5}{|c|}{ weight loss per week* } \\
\hline $0.5-1 \mathrm{~kg}$ & $97(58 \%)$ & $49(36 \%)$ & $146(48.6 \%)$ & \multirow[t]{3}{*}{0.001} \\
\hline $2-4 \mathrm{~kg}$ & $56(33.5 \%)$ & $70(52.6 \%)$ & $126(42 \%)$ & \\
\hline$>4 \mathrm{~kg}$ & $14(8.3 \%)$ & $14(10.5 \%)$ & $28(9.3 \%)$ & \\
\hline \multicolumn{5}{|c|}{ diet successful by dietitian* } \\
\hline Yes & $44(26.3 \%)$ & $53(39.8 \%)$ & $97(32.3 \%)$ & \multirow[t]{2}{*}{0.031} \\
\hline No & $93(55.6 \%)$ & $56(42.1 \%)$ & $149(49.6 \%)$ & \\
\hline \multicolumn{5}{|l|}{ food serving* } \\
\hline Yes & $72(43.11 \%)$ & $76(57.1 \%)$ & $148(49.3 \%)$ & \multirow[t]{2}{*}{0.047} \\
\hline No & $83(49.7 \%)$ & $48(36.0 \%)$ & $131(43.6 \%)$ & \\
\hline \multicolumn{5}{|l|}{ Breakfast* } \\
\hline Yes & $95(56.8 \%)$ & $91(68.4 \%)$ & $186(62 \%)$ & \multirow[t]{2}{*}{0.027} \\
\hline No & $72(43.11 \%)$ & $42(31.5 \%)$ & $114(38 \%)$ & \\
\hline \multicolumn{5}{|l|}{ Exercise* } \\
\hline Yes & $96(57.4 \%)$ & $91(30.3 \%)$ & $187(62.3 \%)$ & \multirow[t]{2}{*}{$>0.034$} \\
\hline No & $71(42.5 \%)$ & $42(14 \%)$ & $113(37.6 \%)$ & \\
\hline Total & 167 & 133 & 300 & \\
\hline
\end{tabular}

According to successful weight loss, there were a number of relationship between the number of successful weight loss attempts and other factors. The first relation was between successful weight loss attempts and type of treatment among participants. participants who were taking special medications for weight loss had more successful weight loss attempts than other types of treatments ( $26 \%$ vs. $5.7 \%$ $\mathrm{p}=0.03$ ) the second relation was between the number of weight loss by kilogram and number of weight loss attempts $\mathrm{P}=(0.001)$. The number of successful weight loss attempts was increase among patients who loss more than 1 kilogram (from 2-4 $\mathrm{kg} /$ week) of their weight (52.6\% vs.36\%). The third relation was number of successful weight loss attempts and described diet by dietitians. (26.3\% of participants had a success attempts less than one times and $39.8 \%$ of them had successful attempts more than one, $p=0.031$. The next relationship was between awareness of participant about food serving and number of successful weight loss. (57\% vs. $36 \%$ had more than one successful weight loss attempts, $\mathrm{p}=0.047$ ). The another relation was between number of successful weight loss and breakfast consumption, (30\% vs. $14 \%, p=0.027)$ There the last relationship was between exercise and the number of successful weight loss attempts,(30.3\% vs. $14 \%$ had more than one successful weight loss attempts $\mathrm{P}=(0.034)$.

\section{DISCUSSION}

The factors that lead to obesity differ according to the condition of people and the environment around them. The sex and age distribution of the participants in the current study was similar to the criteria for previous studies (26-28). The proportion of females was about 1: 5 more than males, with ages 
ranging from 15 to 35 years. There was a significant correlation between body mass index and body weight with many social factors that were addressed in the current study such as gender, hours of work, marital status, and number of children. These results have been proven by previous studies. (56,26,29-30) Despite these correlations, there was no relationship between these factors and the frequency of weight loss attempts. The health problems of chronic diseases and taking special medicines are one of the reasons that effect the process of losing weight in many previous studies ${ }^{11-13 \text {, }}$, but the results of this study showed only a association between the presence of health problems, especially ovarian cysts, and BMI $(\mathrm{p}=0.000)$. Regarding medications, unlike other studies, the current study did not record any association between consumption of contraceptives or endocrine medications with body weight or body mass index, or even with repeated weight loss. However, all patients with thyroid dysfunction particularly if they are overweight, they should receive dietary advice. ${ }^{31}$

Among the factors that are associated with the frequency of weight loss attempts, genetic factor was the most affecting, as more than four weight-loss attempts were reported by participants who are obese and have obesity family history. These findings have confirmed by a number of published studies. ${ }^{(32,33)}$ It was also found in this study a statistically significant relationship between trying to lose weight and psychological problems. Those who complain with an increased desire to eat during a diet or when feeling stressed or suffer from dissatisfaction and a negative outlook on the body, reported an increase in the number of attempts to lose Weight along with its correlation to BMI $\mathrm{P}=(0.000)$. Similar results from the previous evidences. ${ }^{5,34}$ A Dutch study examined whether mindfulness-based strategies can effectively reducing the desire to eating more ,and reduction of automatic relations between urge and reaction.(Participants who were exposed to a 7-week acceptance-based craving intervention reported significantly lower food desiring compared to participants who did not receive this training.). ${ }^{29}$

In this study less than half of participants followed diet by themselves and only $7 \%$ followed diet is described by dietitian. In fact, this study found a relationship between dietary inquiries during the visit and the success of the diet $\mathrm{P}=(0.000)$. The success of the diet linked to the attempts to lose weight and the attempts to succeed the diet, the people who reported the success of the diet, had the lowest rate of attempts to lose weight, and the most in the number of successful attempts. This study indicates that the duration of the most frequent diet was at least a year, followed by a month, and less than a month. The maintenance of losing a period starting from 6 months, as the previous studies reported. ${ }^{35}$ there is no relationship between the duration of the diet and the number of attempts, but there is a relationship between the period of follow-up and the duration of weight maintenance $\mathrm{P}=(0.000)$.

There are a number of diet behavioral factors that linked to an effect on weight loss. As mentioned in previous literature, these factors included TV hours and a fast eating rate have shown to be associated with the frequency of weight loss attempts. ${ }^{(21,36-37)}$. Therefore, it is important to considered it in weight management additionally to follow diet with appropriate amount and type of food. Study was conducted in Bangladesh found that skipping breakfast is associated with greater chance to gain weight. ${ }^{23}$ The current study confirmed this result and found relation also between skipping breakfast and the number of attempts of successful weight loss diet. Exercise is one of the factors that have proven effective in weight loss program. most of previous studies confirmed that exercise has many roles including increase the rate of metabolism, improving digestion and helping to achieve weight loss and maintain it ${ }^{38,39}$ The current 
study indicated that there is a relationship between exercise and the number of successful attempts on the diet . Drinking enough water had great resonance in previous literature to improve digestion and promote weight loss ${ }^{40}$, but this study did not show a correlation between drinking water and the number of weight loss attempts or success. Other factors that have effect on weight loss and gain, short sleep duration and record of sleep disturbances are a feature of obesity ${ }^{24,25}$. In contrast this study did not find a relationship between short sleep rate and body mass index or number of attempts.

That behavior modification may represent a significant progress in obesity treatment, as the groups who lost weight with the behavior modification reported a greater weight loss than other groups, therefore it is important to consider behavior modification in the treatment of obesity. ${ }^{41,42}$

\section{CONCLUSION AND RECOMMENDATIONS}

This study indicates that female presented the highest numbers of over weight than male, and there was clear relation between working hours, marital status and BMI. There was also significant between weight loss attempts and hereditary factor. Psychological factors were the most influential factors on repeated weight loss attempts followed by behavior related factors, so practices related to self-control, mental control, stress reduction practices, and behavior modification must be considered when starting to manage weight. Further studies are recommended also to assess and determine the factors affecting weight loss. Establish educational program to improve and raise awareness about healthy eating habits and eating practicing.

\section{Acknowledgement: None}

Conflict of Interest: None

Source of Funding: None

\section{Ethical Approval: Approved}

\section{REFERENCES}

1. WHO - Obesity and overweight. Fact sheet Nr. 311, Updated March 2011.

2. Finkelstein EA, Khavjou OA, Thompson H, Trogdon JG, Pan L, Sherry B, Dietz W. Obesity and severe obesity forecasts through 2030. American journal of preventive medicine. 2012 Jun 1;42(6):56370.

3. Contreras JE, Santander C, Bravo J. Correlation between age and weight loss after bariatric surgery. Obesity surgery. 2013 Aug 1;23(8):1286-9.

4. St Peter SD, Craft RO, Tiede JL, Swain JM. Impact of advanced age on weight loss and health benefits after laparoscopic gastric bypass. Archives of Surgery. 2005 Feb 1;140(2):165-8.

5. Wu B, O'Sullivan A. Sex differences in energy metabolism need to be considered with lifestyle modifications in humans. J Nutr Metab 2011; 2011: doi: 10.1155/2011/391809; [Epub 2011 Jun .

6. Donnelly JE, Hill JO, Jacobsen DJ et al. Effects of a 16-month randomized controlled exercise trial on body weight and composition in young, overweight men and women: the Midwest ExerciseTrial. Arch Intern Med 2003; 163: 1343-1350.

7. Field AE, Aneja P, Austin SB, Shrier LA, De Moor C, Gordon-Larsen P. Race and gender differences in the association of dieting and gains in BMI among young adults. Obesity. 2007 Feb;15(2):456-64.

8. Zhang C, Rexrode KM, van Dam RM, Li TY, Hu FB. Abdominal obesity and the risk of all-cause, cardiovascular, and cancer mortality: sixteen years of follow-up in US women. Circulation. 2008;117:1658-1666.

9. Calle EE, Rodriguez C, Walker-Thurmond K, Thun MJ. Overweight, obesity, and mortality from cancer in a prospectively studied cohort of US adults. New England Journal of Medicine. 2003 Apr 24;348(17):1625-38.

10. Ríos-Prego M, Anibarro L, SánchezSobrino P. Relationship between thyroid dysfunction and body weight: a not so evident paradigm. International Journal of General Medicine. 2019;12:299.

11. Norris SL, Zhang X, Avenell A, Gregg E, Schmid CH, Kim C, Lau J. Efficacy of 
pharmacotherapy for weight loss in adults with type 2 diabetes mellitus: a metaanalysis. Archives of Internal Medicine. 2004 Jul 12;164(13):1395-404.

12. Panidis D, Farmakiotis D, Rousso D, Kourtis A, Katsikis I, Krassas G. Obesity, weight loss, and the polycystic ovary syndrome: effect of treatment with diet and orlistat for 24 weeks on insulin resistance and androgen levels. Fertility and sterility. 2008 Apr 1;89(4):899-906.

13. Block JP, He Y, Zaslavsky AM, Ding L, Ayanian JZ. Psychosocial stress and change in weight among US adults. American journal of epidemiology. 2009 Jul 15;170(2):181-92.

14. Tlili F, Mahjoub A, Lefevre P, Bellaj T, Ben Romdhane H, Eymard-Duvernay S, Holdsworth M. Tunisian women's perceptions of desirable body size and chronic disease risk. Ecology of food and nutrition. 2008 Aug 1;47(4):399-414.Social factors

15. Massey A, Hill AJ. Dieting and food craving. A descriptive, quasi-prospective study. Appetite. 2012 Jun 1;58(3):781-5.

16. Zellner DA, Loaiza S, Gonzalez Z, Pita J, Morales J, Pecora D, Wolf A. Food selection changes under stress. Physiology \& behavior. 2006 Apr 15;87(4):789-93.

17. Green AR, Larkin M, Sullivan V. Oh stuff it! The experience and explanation of diet failure: an exploration using interpretative phenomenological analysis. Journal of Health Psychology. 2009 Oct;14(7):9971008

18. Sares-Jäske L, Knekt P, Männistö S, Lindfors O, Heliövaara M. Self-report dieting and long-term changes in body mass index and waist circumference. Obesity science \& practice. 2019 Aug;5(4):291-303.

19. Kruger J, Blanck HM, Gillespie C. Dietary and physical activity behaviors among adults successful at weight loss maintenance. International Journal of Behavioral Nutrition and Physical Activity. 2006 Dec 1;3(1):17.

20. Larsen TM, Dalskov SM, van Baak M, Jebb SA, Papadaki A, Pfeiffer AF, Martinez JA, Handjieva-Darlenska T, Kunešová M, Pihlsgård M, Stender S. Diets with high or low protein content and glycemic index for weight-loss maintenance. New England Journal of Medicine. 2010 Nov 25;363(22):2102-13.
21. Raynor DA, Phelan S, Hill JO, Wing RR. Television viewing and long-term weight maintenance: results from the National Weight Control Registry. Obesity. 2006 Oct;14(10):1816-24.

22. Islam MS, Goon S. Breakfast Skipping and Obesity Risk Among Urban Adults in Bangladesh. International Journal of Public Health Science.2014Mar;3(1):7174.

23. Timlin MT, Pereira MA. Breakfast frequency and quality in the etiology of adult obesity and chronic diseases. Nutrition reviews. 2007 Jun 1;65(6):268-81.

24. Vgontzas AN, Bixler EO, Chrousos GP, Pejovic S. Obesity and sleep disturbances: meaningful sub-typing of obesity. Archives of physiology and biochemistry. 2008 Jan 1;114(4):224-36.

25. Vgontzas AN, Lin HM, Papaliaga M, Calhoun S, Vela-Bueno A, Chrousos GP, Bixler EO. Short sleep duration and obesity: the role of emotional stress and sleep disturbances. International journal of obesity. 2008 May;32(5):801-9.

26. $\mathrm{Au} \mathrm{N}$, Hauck K, Hollingsworth $\mathrm{B}$. Employment, work hours and weight gain among middle-aged women. International Journal of Obesity. 2013 May;37(5):718-24

27. Alberts HJ, Mulkens S, Smeets M, Thewissen R. Coping with food cravings. Investigating the potential of a mindfulnessbased intervention. Appetite. 2010 Aug 1;55(1):160-3.

28. Troisi A. Patients “ Motivations, Expectations, and Experiences. InBariatric Psychology and Psychiatry 2020 (pp. 1321). Springer, Cham.

29. Olson CM, Strawderman MS, Hinton PS, Pearson TA. Gestational weight gain and postpartum behaviors associated with weight change from early pregnancy to $1 \mathrm{y}$ postpartum. International journal of obesity. 2003 Jan;27(1):117-27.

30. Bobrow KL, Quigley MA, Green J, Reeves GK, Beral V. Persistent effects of women's parity and breastfeeding patterns on their body mass index: results from the Million Women Study. International journal of obesity. 2013 May;37(5):712-7.

31. O'Malley B, Hickey J, Nevens E. Thyroid dysfunction-weight problems and the psyche: the patientes'perspective. J Hum Nutr Diet.2000;13:243-248. doi:10.1046/j.1365-277x.2000.00238.x . 
32. Calugi S, Marchesini G, El Ghoch M, Gavasso I, Dalle Grave R. The association between weight maintenance and sessionby-session diet adherence, weight loss and weight-loss satisfaction. Eating and Weight Disorders-Studies on Anorexia, Bulimia and Obesity. 202Feb;25(1):127-33.

33. Calugi S, Marchesini G, El Ghoch M, Gavasso I, Dalle Grave R. The influence of weight-loss expectations on weight loss and of weight-loss satisfaction on weight maintenance in severe obesity. Journal of the Academy of Nutrition and Dietetics. 2017 Jan 1;117(1):32-8.

34. Heber D. An Integrative View of Obesity. Am J ClinNutr. 2010;9:280S-283S.

35. Elfhag $\mathrm{K}$, Rössner $\mathrm{S}$. Who succeeds in maintaining weight loss? A conceptual review of factors associated with weight loss maintenance and weight regain. Obesity reviews. 2005 Feb;6(1):67-85.

36. Ohkuma T, Hirakawa Y, Nakamura U, Kiyohara Y, Kitazono T, Ninomiya $\mathrm{T}$. Association between eating rate and obesity: a systematic review and meta-analysis. International journal of obesity. 2015 Nov;39(11):1589-96.

37. Ohkuma T, Fujii H, Iwase M, Kikuchi Y, Ogata S, Idewaki Y, Ide $\mathrm{H}$, Doi $\mathrm{Y}$, Hirakawa Y, Mukai N, Ninomiya T. Impact of eating rate on obesity and cardiovascular risk factors according to glucose tolerance status: the Fukuoka Diabetes Registry and the Hisayama Study. Diabetologia. 2013 Jan 1;56(1):70-7.
38. Miller WC, Koceja DM, Hamilton EJ. A meta-analysis of the past 25 years of weight loss research using diet, exercise or diet plus exercise intervention. International journal of obesity. 1997 Oct;21(10):941-7.

39. Andrade AM, Coutinho SR, Silva MN, Mata J, Vieira PN, Minderico CS, Melanson KJ, Baptista F, Sardinha LB, Teixeira PJ. The effect of physical activity on weight loss is mediated by eating self-regulation. Patient Education and Counseling. 2010 Jun 1;79(3):320-6.

40. Dennis EA, Dengo AL, Comber DL, Flack KD, Savla J, Davy KP, Davy BM. Water consumption increases weight loss during a hypocaloric diet intervention in middle-aged and older adults. Obesity. 2010 Feb; 18(2):300-7.

41. Penick SB, Filion R, Fox S, Stunkard AJ. Behavior modification in the treatment of obesity. Psychosomatic Medicine. 1971 Jan 1;33(1):49-56.

42. Toulabi T, Nikoo MK, Amini F, Nazari H, Mardani M. The influence of a behavior modification interventional program on body mass index in obese adolescents. Journal of the Formosan Medical Association. 2012 Mar 1;111(3):153-9.

How to cite this article: Souad El-mani, Ali Ateia Elmabsout, Abdullah Sheikhi et.al. Factors influencing weight loss attempts and long term weight loss maintenance. Int $J$ Health Sci Res. 2021; 11(12): 205-216. DOI: https:// doi.org/10.52403/ijhsr.20211227 